\title{
Integrated Lessons in the Subjects of Self-Knowledge and World Knowledge in the Elementary Grades
}

\author{
Kuralbayeva A.A. \\ H.A. Yassawi International Kazakh-Turkish University. B. Sattarhanov Avenue 29, 161200 Turkistan, main campus, Kazakhstan; \\ kural-aliya84@mail.ru \\ Yerimbetova G.
}

H.A. Yassawi International Kazakh-Turkish University. B. Sattarhanov Avenue 29, 161200 Turkistan, main campus, Kazakhstan

Khalilayeva E.

H.A. Yassawi International Kazakh-Turkish University. B. Sattarhanov Avenue 29, 161200 Turkistan, main campus, Kazakhstan

B.N. Auezov

H.A. Yassawi International Kazakh-Turkish University. B. Sattarhanov Avenue 29, 161200 Turkistan, main campus, Kazakhstan

A.K. Zhundibayeva

Shakarim State University of Semey, Glinky str., No. 20 A, 071410, Semey, East Kazakhstan region, Kazakhstan

\section{Doi:10.5901/mjss.2015.v6n6s1p84}

\section{Abstract}

In this article the concept of integration and theoretical problems of implementation of intersubject communications are considered. The positive influence of the integrated training on the development of cognitive activity and interests of being trained of elementary classes are specified. The modern educational system is directed on the formation of well-educated, intellectually developed personality with complete representation of the world picture, with understanding of depth of communications of the phenomena and the processes representing this picture. In elementary classes pupils have formed the main positive relations to educational activity, and through the integrated lessons they have an increase of cognitive interests and cognitive motivation. It was characterized the development of emotional communication to lessons and formation of activization of educational-cognitive activity of pupils through carrying out of integrated lessons in elementary classes.

Keyword: integration, integrated lessons, intersubject communications, educational-cognitive activity.

\section{Introduction}

The modern education system is directed on formation of highly educated, intellectually developed personality with complete representation of a picture of the world, with understanding of depth of communications of the phenomena and the processes representing this picture. Subject dissociation becomes one of the reasons of a fragmentariness of outlook of pupils of school while in the modern world tendencies to economic, political, cultural, information integration prevail. Thus, independence of subjects, their weak communication with each other generates serious difficulties in formation at pupils of a complete picture of the world, interfere with organic perception of culture.

Now in our country there is a process of formation of new model of the education system focused on occurrence into world educational space, being characterized considerable changes in the pedagogical theory and practice of teaching and educational process. The thought of transition of pedagogical science on a new stage of development, from extensive to intensive methods of training, from information and explanatory technologies to activity developing, forming a wide range of personal qualities of school students became conventional.

Idea of modernization of education at elementary school through integration of subjects according to which the education purpose at the first step is connected with protection and strengthening of physical and mental health of school students of initial classes, ensuring their emotional wellbeing; development of the child as subject of the relations with people, with the world, with itself; preservation and support of identity of each school student.

At an initial step of training integration of subjects into a whole is most effective as the younger school student completely perceives world around, and for it there shouldn't be borders between subjects. 
Nowadays, it might be possible to speak with confidence about the fact of emergency of new tendencies in definition of role and nature of development of educational system in Kazakhstan. These tendencies have global character and coincide with similar tendencies not only in European, but also in many other countries of the world.

Elementary school is a self-valuable, essentially new stage in the life of the child: it begins the systematic training in educational institution, the sphere of its interaction with world around extends, the social status changes and the needing for self-expression increases.

Primary education has the own features which are sharply distinguishing it from all subsequent stages of systematic school education. On this period there is a formation of bases of educational activity, cognitive interests and cognitive motivation; under favorable conditions of training there is a formation of consciousness and a self-assessment of the child.

Introduction of integrated subjects in primary educational system positively influences on the development of independence, cognitive activity and interests of being trained. The results of the integrated training are shown in the development of creative thinking of pupils.

Indicator of intellectual development of the pupil is a transfer of knowledge from one subject in another which characterizes efficiency of cognitive activity. The transfer concludes in intersubject generalization of known and synthesizing of the new and generalized knowledge. Intersubject communications in training bring creativity elements in cogitative activity of the pupil, and also elements of a reproduction and the search, being shown in cognitive activity.

\section{Methods}

Methods of I. V. Koshmina "Intersubject communications in elementary school", and A. Mukhambetzhanova "Theoreticalmethodological bases of formation of a scientific picture of the world at pupils by integration tools of primary education" were used, in data processing of analyses of the integrated lessons the methodical development of Chesnokova N. P. were used which was called "Integration of problems of moral and spiritual development of children on educational system: The collection of methodical development of the integrated lessons".

\section{Results}

For the purpose of practical justification of the conclusions received during theoretical studying of a problem "The integrated lessons of subjects of self-knowledge and world knowledge of primary classes" was carried out in research work.

Pupils of the second classes of school lyceum No. 4 (2 experimental classes - have 56 schoolchildren) and secondary school named after M. Abenova (2 control classes - have 52 schoolchildren) in city Turkistan took part in the experiment.

Experimental work was carried out during the academic year and provided two stages:

$1^{\text {st }}$ stage is studying of motives of cognitive interests of educational activity of schoolchildren and the emotional relation to the integrated lessons.

$2^{\text {nd }}$ stage is formation of activization of educational and cognitive activity of pupils in the integrated lessons.

At the first stage the questions for the purpose of definition of existence of positive motivation to educational activity and the analysis of the relation of the pupil to subjects were carried out. Results were estimated on five-point system and shown on the Table I and on the figure -1 .

Table I. The Influence of Students' Relation to the Subjects

\begin{tabular}{|c|c|c|c|c|c|c|c|c|c|}
\hline \multirow[b]{2}{*}{ Pupil's Relation } & \multicolumn{9}{|c|}{ School subject } \\
\hline & 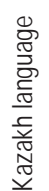 & 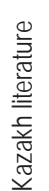 & 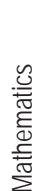 & 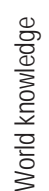 & 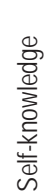 & 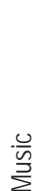 & $\begin{array}{l}\stackrel{0}{ \pm} \\
\stackrel{\Xi}{ \pm} \\
\stackrel{\Xi}{*}\end{array}$ & 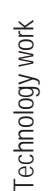 & 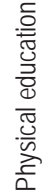 \\
\hline I like this subject & & & & & & & & & \\
\hline I don't like this subje & & & & & & & & & \\
\hline I want to be engagec & & & & & & & & & \\
\hline I don't want to be en & & & & & & & & & \\
\hline Make to be engaged & & & & & & & & & \\
\hline Do not give answer & & & & & & & & & \\
\hline In total scores & & & & & & & & & \\
\hline
\end{tabular}




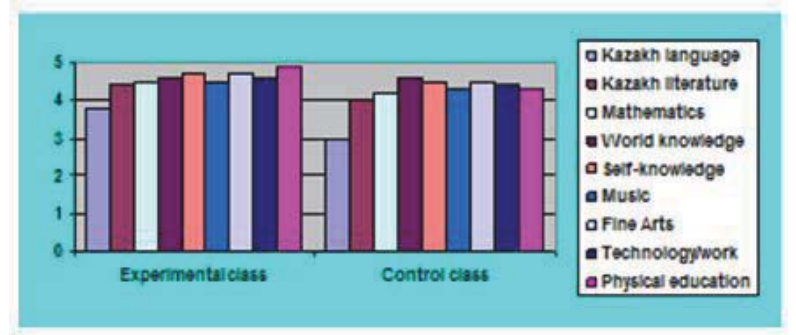

Figure 1. Comparative analysis of students' relation to the subjects

For more interesting and successful assimilation of the program and for identification of the level of the emotional relation to the integrated lessons and to activizations of educational and cognitive activity of pupils in the integrated subjects lessons of world knowledge and self-knowledge were carried out in the experimental classes. The emotional relation of schoolchildren to the integrated lessons on the questions results are shown in the figure No. 2 in percentage.

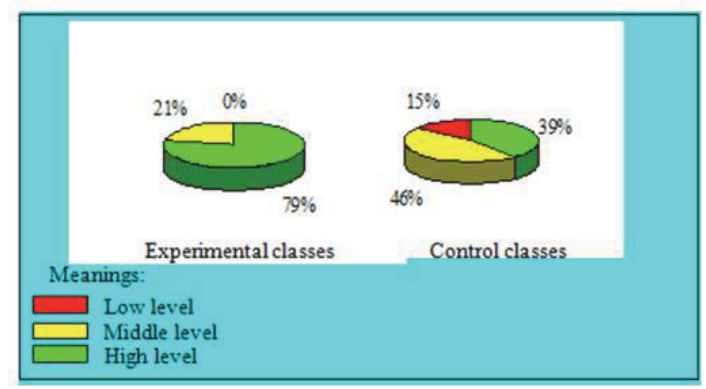

Figure 2. The level of emotional relation of schoolchildren to integrated subjects

At the second stage on the identification levels of the emotional relation during carrying out the world knowledge and selfknowledge of integrated lessons activity increase to informative activity at school students was obviously observed. In this connection the comparative analysis of increase of cognitive activity of schoolchildren of experimental and control classes were made. Results of the comparative analysis are shown in the figure -3.

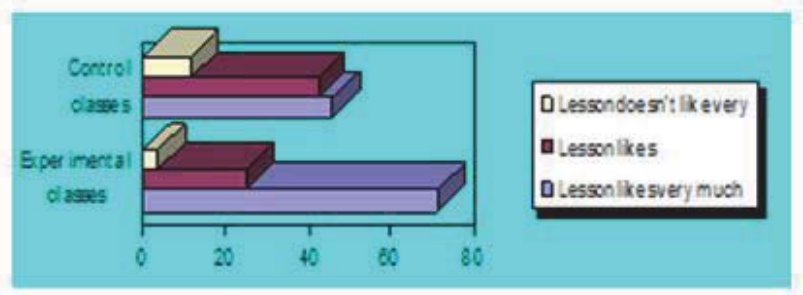

Figure 3. The comparative analysis of increase of cognitive activity of schoolchildren after carrying out the integrated lessons

Diagnostics was carried out in the form of monitoring of ZUN received after studying of subjects. For example, the pupils of experimental and control classes were given separately test works on world knowledge on a subject: "We learn to understand the nature" and on natural study on a subject: "Conditions necessary for life of plants". Pupils of control classes studied these subjects at usual lessons of self-knowledge and world knowledge, and in the experimental classes the integrated lessons were conducted. The integrated lessons of self-knowledge and world knowledge were carried out 
on all interconnected subjects. There were received the following results of test works on all conducted integrated lessons percentage of these qualities of knowledge which are reflected in the figure -4 .

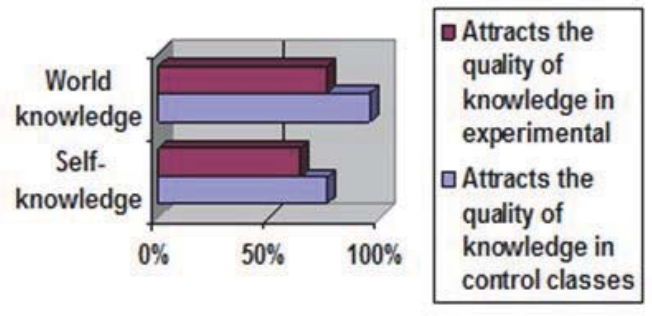

Figure 4. Total of quality of knowledge in experimental and control classes

In the result of research work the following conclusions were received:

- after carrying out of experiment the level of informative interest raised;

o there were changes in the relations of pupils to the scientists and to school subjects;

- the integrated lessons raised an emotional spirit in a class, opportunity for manifestation of individual creative abilities of children;

- children became more sociable, relaxed in judgments, they increased aspiration to study, not afraid of difficulties they were glad to have new knowledge;

- activization of educational-cognitive activity of pupils was created.

Carrying out monitoring of progress of pupils in a year, we want to note that subjects on which the integrated lessons were conducted, which are acquired by pupils better than considered at traditional lessons. Taking into account carried-out questions, conversations, carrying out of control tasks on the integrated subjects of $94 \%$, and quality fluctuates from $67 \%$ to $92 \%$. It means that the integrated lessons improve and facilitate training process in elementary classes, increase interest to study and stimulate the best formation of educational skills and abilities of schoolchildren.

\section{Discussion}

"Integration is an association as a whole any parts of elements". Such definition is given by the explanatory dictionary of foreign words and "The logical dictionary reference" by N. I. Kondakov.

"Integration is the party of development connected with association in whole of earlier versatile parts and elements". Such definition is given by "The philosophical dictionary" and supplements with the following signs: "These processes can take place as in already developed system (in this case they conduct to increase of level of its integrity and organization), and at emergence of new system from earlier untied elements" [Philosophical encyclopedic dictionary, 1983].

Methodical basis of an integrated approach is establishment of intra subject and intersubject communications in assimilation of bases of sciences and understanding of regularities of all existing in the world. And it is possible on condition of repeated return to concepts at different lessons, their deepening and enrichment, exarticulation of essential signs available to these ages, concepts. Therefore, any lesson can be taken for a basis of integration with its established structure and logic of carrying out in which substantial party that group of concepts which treats this subject will be included, but on the integrated lesson knowledge, results of the analysis of concept from the point of view of other sciences, other subjects is attracted. grounded:

By Kazakhstan scientist A.A. Beysenbayeva the complex of signs and functions of intersubject communications is

- the main signs of intersubject communications as most important means of formation of cognitive interest at schoolchildren are the integrativity, selectivity and variability;

- intersubject communications are rather steady pedagogical phenomenon of the organization and interaction of elements as a result of which new qualities are shown, certain new whole, in particular, such personal quality, as cognitive interest is born;

- as a part of whole intersubject communications carry out a set of functions, such as: educational, developing, bringing up and constructive [Beysenbayeva, 1970]. 
To the problem of integration of training and education at elementary school it is important and modern both for the theory, and for practice. Its relevance is dictated by the new social inquiries shown to school, and caused by changes in the science and production sphere.

The integrated lesson is a special type of the lesson uniting in training at the same time on several disciplines at studying of one concept, a subject or the phenomenon. Efficiency of integration depends on several factors: successful combination of the subjects, studied subjects, thorough training of the teacher and spirit of schoolchildren for work; selection, combinations of methods, receptions taking into account age opportunities of children.

The integrated lessons are a creativity of the teacher where great pedagogical opportunities are realized. At such lessons pupils receive many-sided knowledge about object of studying; they form ability to transfer knowledge from one field of knowledge to another. The essence of such lessons consists in association of efforts of teachers of different subjects for its preparation and carrying out, and also in integration of knowledge about a certain object of studying.

Joining discussions, reflections, searches, opening become leading methods of training. The pupil of elementary classes acquires the right to initiative, independence, and individual searching. Integration gives the chance to the teacher for self-realization, self-expression and creativity. It is promoted by specifics of a technique of preparation and carrying out the integrated lesson.

Signs of the integrated lesson in elementary classes:

1) Specially organized lesson, i.e. if it is not specially organized, it cannot be general or it breaks up to the separate lessons which haven't been united by a common goal;

2) purpose specific (integrated); it can be put, for example, for

1. deeper penetration into an essence of a studied subject;

2. increases of interest of pupils to the subjects which are taught in elementary classes;

3. the complete, synthesized perception of questions studied on this subject;

4. economy of school hours, etc.;

3) wide use of knowledge from different disciplines, for example, natural study, self-knowledge, native language, fine arts, manual skills, mathematics, physical training, i.e. profound implementation of intersubject communications. conditions:

During the planning and the organization of such lessons it is important to teacher to consider the following

1. In the integrated lesson the blocks of knowledge of two-three various subjects are united, therefore it is extremely important to define a main goal of the integrated lesson. If the common goal is defined, from the maintenance of subjects undertake only those data which are necessary for its realization.

2. Integration promotes removal of tension, an overload, weariness of pupils of elementary classes, and it is very important factor, at the expense of their switching on various kinds of activity, in particular game, during a lesson. On the planning the careful definition of optimum loading by different types of activity of pupils at a lesson is required.

3. On carrying out the integrated lesson by teachers (conducting different subjects) careful coordination of actions is required.

\section{Conclusion}

Introduction of the integrated system can be from bigger degree than traditional subject training, which promote development of widely erudite person possessing complete outlook, ability independently to systematize knowledge available for it and non conventionally to approach to the solution of various problems.

The integrated lessons expand a framework of a usual lesson; it means the possibility of development of creative abilities of each pupil increases. Integration allows teaching pupils to get knowledge independently, to raise intellectual level, to develop interest to the science, to broaden their horizons, to develop potential opportunities of younger schoolchildren. On carrying out the integrated lessons such problem as the individual differentiated approach in training of children with different abilities is solved. The integrated lessons are pleasant to children, cause in them interest to knowledge, give them a lot of new, useful things, they contain a big emotional charge. These lessons help formation of spelling vigilance, development of speech and enrichment of a lexicon of children, develop esthetic taste, ability to understand and appreciate works of art, beauty and richness of the native nature, creative potential. 


\section{References}

Beysenbayeva A.A. Value of intersubject communications in school study: dissertation. Almaty, 1970, 164 p.

Chesnokova N.P. Integration of problems of moral and spiritual development of children on educational system: The collection of methodical development of the integrated lessons. Karaganda: RIO IPK and PGSRO. 2009.

Kondakov N.I. Logical dictionary reference. Moscow: Science, 1975. 595 p.

Koshmina I.V. Intersubject communications at elementary school. Moscow: VLADOS, 2003. 144 p.

Mukhambetzhanova A. Theoretical-metodological bases of formation of a scientific picture of the world at pupils integration tools of primary education: Author's thesis. Almaty, 2001, $45 \mathrm{p}$.

Philosophical encyclopedic dictionary. Moscow: Soviet encyclopedia, 1983. 